\title{
Study of Cellulose Interaction with Concentrated Solutions of Sulfuric Acid
}

\author{
Michael Ioelovich \\ Chemical Department, Designer Energy Ltd., Bergman Street, Rehovot 76100, Israel \\ Correspondence should be addressed to Michael Ioelovich, bd895892@zahav.net.il \\ Received 5 October 2012; Accepted 4 November 2012 \\ Academic Editors: C. Perego and I. Poulios
}

Copyright () 2012 Michael Ioelovich. This is an open access article distributed under the Creative Commons Attribution License, which permits unrestricted use, distribution, and reproduction in any medium, provided the original work is properly cited.

The effect of the concentration of sulfuric acid (SA) and temperature on structure and properties of cellulose (MCC) had been studied. Investigations showed that solubility of the initial sample at the room temperature increased gradually in the range of the acid concentration from 50 to $60 \mathrm{wt} . \%$ SA. When SA concentration reached $65 \mathrm{wt} . \%$, then MCC sample dissolved completely. Cellulose regenerated from $65 \mathrm{wt} . \%$ SA had an amorphized structure and was characterized by high enzymatic digestibility. At increased temperature, $45^{\circ} \mathrm{C}$, solubility of MCC in SA was raised, while yield and DP decreased. After treatment of MCC with hot 50-60 wt.\% SA, the crystallinity degree of the obtained cellulose samples changed slightly, and these samples retained mainly the CI crystalline polymorph. However, when SA concentration reached $65 \mathrm{wt} . \%$, then regenerated cellulose had CII crystalline polymorph, reduced crystallinity degree, and low DP. Using optimal conditions of the acidic treatment $\left(57-60 \mathrm{wt} . \% \mathrm{SA}, \mathrm{T}=45^{\circ} \mathrm{C}\right.$; $t=1 \mathrm{~h}$ ) in combination with the high-power disintegration permitted obtaining the CI nanocrystalline cellulose particles (NCP) having sizes 150-200 × 10-20 nm with the heightened yield (65-70\%). These NCP can be used, for example, as reinforcing nanofillers for various composites.

\section{Introduction}

The first investigations of cellulose interaction with concentrated sulfuric acid (SA) began in the end of the 19th century and obtained the wide spread in the 20th century with the purpose to develop the methods for dissolution and hydrolysis of cellulose materials [1-6]. These early investigations showed that at room or lower temperatures, the sulfuric acid with concentrations greater than 62-63wt.\% caused swelling and dissolving of cellulose samples that was accompanied by hydrolysis process. Increased temperatures of the acidic treatment promoted both to hydrolysis and dissolving of cellulose $[6,7]$. Cellulose samples having the distorted structure dissolved in 63-65 wt.\% SA better than the structural-ordered celluloses [8]. After dilution of the solution, the cellulose precipitated in a modified swollen structural form called "hydrocellulose" [9].

If concentration of SA was high enough, usually 72 wt.\%, then after acidic treatment at room temperature the cellulose hydrolyzed with forming of water-soluble oligomers $[7,10]$.
The following boiling of the diluted acidic solutions permitted to convert the oligomers mainly into glucose. The similar procedure was also used for determination content of Klason's lignin in the plant materials [10-14].

At increased concentrations $>63$ wt. $\%$ molecules of sulfuric acid are capable to break the hydrogen bonds and penetrate into noncrystalline and crystalline domains of the polymer with forming of the complexes [6]. Moreover, the partial esterification of hydroxyl groups of cellulose and their substitution by sulfate groups was observed [15-17]. Breaking of hydrogen bonds as a result of the forming of the complexes and sulfate esters and the depolymerization of macromolecular chains, are the main factors causing the cellulose dissolution in the enough-concentrated sulfuric acid solutions.

In the last decade of the 20th century and the first decade of the 21th century, interest to the deep study of interaction between cellulose and sulfuric acid was raised due to intensive study of nanoscale cellulose particles and its based composites. As known, the nanocrystalline particles (NCP) are 
characterized by increased crystallinity, developed specific surface, improved dispersion ability, biodegradability, as well as stability to aggressive medium, and elevated temperatures and proteolytic enzymes [18-23]. Due to these features, NCP can be used as high-quality reinforcing filler for polymers and biodegradable materials, strengthening additive for papers, thickener for dispersions, drug's carrier, implant, and so forth.

The NCP can be made by treatment of celluloses of various origins with concentrated sulfuric acid solutions at various temperatures with the following high-power mechanical or ultrasound disintegration of the acid-treated cellulose in water. The concentration of sulfuric acid can vary from 45 to $70 \mathrm{wt} . \%$, the temperature can range from 25 to $70^{\circ} \mathrm{C}$, and the treatment time can be from $30 \mathrm{~min}$ to overnight depending on the temperature [19-22, 24].

At concentrations of sulfuric acid from 45 to $60 \mathrm{wt} . \%$, the high-crystalline NCP having CI crystalline polymorph were isolated [21, 25-28]. On the other hand, also higher concentrations of SA, 64-65 wt.\%, were recommended to obtain the high-crystalline CI nanoparticles by means of the acidic treatment of cellulose materials at $45-60^{\circ} \mathrm{C}$ for $0.5-$ $2 \mathrm{~h}$ [29-31]. On the contrary, it was shown that treatment of the initial cellulose with hot $64 \mathrm{wt} . \%$ SA led to decreasing in crystallinity of obtained nanoparticles [32].

In the other papers $[4,6,7,21,33,34]$, it was found that, the sulfuric acid at concentrations greater than 63-64 wt.\% causes swelling and dissolving of cellulose samples. When the acidic solution of cellulose was diluted with water the soluble cellulose was regenerated and precipitated in a form of lowmolecular amorphized flocs having crystalline polymorph of CII-type [21,33-35]. After disintegration of these flocs in water medium, the low-molecular particles can be isolated. Depending on the disintegration technique and conditions, the particles of the regenerated cellulose can have the various shapes-both elongated and spherical [33,34].

So, contrary to statements about the high-crystalline structure of the nanoparticles obtained by treatment of initial cellulose materials with $64-65 \mathrm{wt} . \%$ SA [29-31], the other experiments adduce evidences about amorphized structural state of these particles [21, 33-35]. The investigations of Hashaikeh et al. [35] showed that at controlled short-time hydrolysis of the cellulose with 64-65 wt.\% SA, the insoluble part of cellulose can have crystalline structure CI, while the cellulose regenerated from acidic solutions always had crystalline polymorph of CII.

Since the existing results about interaction between cellulose and sulfuric acid were ambiguous, the detailed investigations are required in order to clarify the dependence of the cellulose structure on the conditions of acidic treatment.

\section{Experimental}

2.1. Parenthetical Remark. To study the interaction between cellulose and solutions of sulfuric acid, the following methodical procedures need to be adhered.

(1) The mixing cellulose with SA solutions should be performed at cooling.
(2) The concentration of SA should be adjusted and measured with accuracy $\pm 0.1 \mathrm{wt} . \%$.

(3) The cellulose feedstock should be in the powdered or fibrillated form.

(4) The initial cellulose must be preliminary swollen in water, and then concentrated SA was slowly added at stirring and cooling to achieve the required final concentration of SA.

Experiments were carried out at room temperature, $25^{\circ} \mathrm{C}$, to study the dissolution process of cellulose or at increased temperature, $45^{\circ} \mathrm{C}$, which is regarded optimal for preparation of nanocellulose [22, 24, 29].

2.2. Materials. Initial cellulose material was the powdered microcrystalline cellulose (MCC) Avicel PH-301 made of FMC BioPolymer Co. This MCC type has average particle size of $50 \mu \mathrm{m}$ and $\mathrm{DP}=170$.

Chemical pure $95 \mathrm{wt} . \%$-sulfuric acid was supplied from Sigma-Aldrich Co. The concentrated SA was diluted dropwise with water at cooling in an ice bath up to $80 \mathrm{wt} . \%$ exactly having density $1.727 \mathrm{~g} / \mathrm{cm}^{3}$.

2.3. Treatment of Cellulose with Sulfuric Acid. The initial MCC sample was mixed with water in a lab glass, and then $80 \mathrm{wt} . \%$ acid (SA) was slowly added at cooling to obtain the required final concentration of SA from 50 to $70 \mathrm{wt} . \%$ and acid/cellulose ratio (ACR) 10 . The glass was placed into water bath having temperature 25 or $45^{\circ} \mathrm{C}$ and heated at stirring for $1 \mathrm{~h}$. After the acidic treatment, contents of the glass were poured out into tenfold volume of cold water at stirring. Cellulose sediment was separated from the liquid phase by centrifugation at the acceleration of $4000 \mathrm{~g}$ for $10 \mathrm{~min}$, and then the acid-treated sample was washed with water, $5 \%$ sodium bicarbonate and finally with distillated water to $\mathrm{pH}$ about 6 , using centrifugation to remove the liquid phase. To obtain the dry sample, the wet sediment was additionally washed with ethanol and acetone and dried at $60^{\circ} \mathrm{C}$ overnight and then at $105^{\circ} \mathrm{C}$ up to constant weight.

Total yield $(Y)$ of the acid-treated cellulose including yields of the insoluble and regenerated parts of cellulose was calculated as follows

$$
Y, \%=100\left(\frac{W}{\mathrm{~W}_{o}}\right),
$$

where $W_{o}$ is initial dry weight of the sample and $W$ is weight of dried sediment.

2.4. Determination of Cellulose Solubility in Sulfuric Acid. The initial MCC sample was treated in a lab glass with 50 $70 \mathrm{wt} . \% \mathrm{SA}$ at ACR $=10$, temperature 25 or $45^{\circ} \mathrm{C}$ for $1 \mathrm{~h}$. The insoluble residual part of the sample was separated from the acid by centrifugation at the acceleration of $4000 \mathrm{~g}$ for $10 \mathrm{~min}$ and then rinsed twofold with the SA solution of the same concentration, washed with water, $5 \mathrm{wt} . \%$ sodium bicarbonate and distillated water up to neutral $\mathrm{pH}$ value. Finally, the cellulose residue was washed with absolute ethanol and 
acetone and dried at $60^{\circ} \mathrm{C}$ overnight and then at $105^{\circ} \mathrm{C}$ up to constant weight.

Solubility $(S)$ of cellulose in solutions of SA was calculated as follows:

$$
S, \%=100\left[1-\left(\frac{W}{W_{o}}\right)\right],
$$

where $W_{o}$ is initial dry weight of the sample and $W$ is dry weight of insoluble part of the sample.

2.5. Enzymatic Hydrolysis of Cellulose Samples. The samples were hydrolyzed with a mixture of commercial cellulolytic enzyme (cellulase) NS50013 and $\beta$-glucosidase NS50010 (Novozymes A/S, Bagsvaerd, Denmark). The loading of cellulase was $5 \mathrm{FPU}$ per $1 \mathrm{~g}$ of solid sample and of $\beta$-glucosidase was $7 \mathrm{CBU}$ per $1 \mathrm{~g}$ of solid sample. Hydrolysis of the samples was carried out in 50-mL polypropylene tubes. The samples containing $1 \mathrm{~g}$ of the solid matter and $10 \mathrm{~mL}$ of $50 \mathrm{mM} / \mathrm{L}$ acetate buffer $(\mathrm{pH}=4.8)$ were put into the tubes. Then cellulase and $\beta$-glucosidase were added. An additional amount of the buffer was supplemented to obtain total volume of the liquid phase $20 \mathrm{~mL}$ and concentration of the cellulose sample $50 \mathrm{~g} / \mathrm{L}$. The tubes closed with covers were placed in a shaker incubator at $50^{\circ} \mathrm{C}$ and shaken at $180 \mathrm{rpm}$ for $48 \mathrm{~h}$. The tubes were centrifuged at the acceleration of $4000 \mathrm{~g}$ for $10 \mathrm{~min}$ in order to separate the cellulose residue from the liquid phase. The sediment was washed with distilled water, with removing the liquid phase by centrifugation. Finally, the cellulose residue was washed with absolute ethanol and acetone and dried at $60^{\circ} \mathrm{C}$ overnight and then at $105^{\circ} \mathrm{C}$ up to constant weight. Conversion degree of cellulose (CD) at the enzymatic hydrolysis was calculated as follows:

$$
\mathrm{CD}=100\left[1-\left(\frac{W}{W_{o}}\right)\right],
$$

where $W_{o}$ is dry weight of the initial sample and $W$ is dry weight of the enzymatic-hydrolyzed sample.

2.6. Determination of Average Degree of Polymerization. The average degree of polymerization (DP) was measured by the viscosity method using diluted solutions of cellulose in Cadoxen [18].

2.7. Preparation of Nano crystalline Particles (NCP). The NCP were prepared according to the following procedure [21]. The initial MCC sample was mixed with water in a lab glass, and then $80 \mathrm{wt} . \%$ sulfuric acid (SA) was slowly added with cooling to obtain the required final acid concentration from 57 to $60 \mathrm{wt} . \%$ and acid/cellulose ratio 10 . The glass was placed into water bath having temperature $45^{\circ} \mathrm{C}$ and heated at stirring for $1 \mathrm{~h}$. After acidic treatment, contents of the glass were poured out into tenfold volume of cold water at stirring. Cellulose sediment was separated from liquid phase by centrifugation at the acceleration of $4000 \mathrm{~g}$ for $10 \mathrm{~min}$; washed with water, $5 \%$ sodium bicarbonate, and finally with distillated water to $\mathrm{pH}$ about 6 . Then the washed cellulose sediment was diluted with distillated water up to solid concentration 2-3 wt.\% and disintegrated by high-pressure homogenizer APV-2000 at pressure $100 \mathrm{MPa}$ during $15 \mathrm{~min}$.

To obtain the dry nanopowder, the following procedure was carried out. The water dispersion of nanoparticles was evaporated in vacuum at $80^{\circ} \mathrm{C}$ to about $10-15 \%$ solid content, washed with absolute ethanol, acetone, and hexane, and finally dried at $50^{\circ} \mathrm{C}$ up to constant weight.

2.8. Determination of Structural Characteristics of Cellulose Samples by XRD. A Rigaku-Ultima Plus diffractometer ( $\mathrm{CuK}_{\alpha}$-radiation, $\lambda=0.15418 \mathrm{~nm}$ ) was used for X-ray investigations. Diffractograms of dry samples were recorded in the $\varphi=2 \Theta$ angle range from 5 to $80^{\circ}$. After recording of the diffractograms, the background was separated, and selected $\mathrm{X}$-ray patterns were corrected and normalized. Then, diffractions from crystalline and noncrystalline regions were separated by a computerized method. Crystallinity degree $(X)$ of the cellulose samples was calculated according to the following [36]:

$$
X=100 \% \frac{\int I_{c} d \varphi}{\int I_{o} d \varphi},
$$

where $I_{c}$ and $I_{o}$ are the corrected and normalized intensities of diffraction from the crystalline part and whole sample, respectively.

Content of CII crystalline polymorph was determined using the XRD calibration method of the inner standards [37]:

$$
\text { CII, } \%=200\left[\frac{I_{12}}{\left(I_{15}+I_{16}\right)}\right] \text {, }
$$

where $I_{12}, I_{15}$, and $I_{16}$ are the corrected and normalized intensities of diffraction from the crystalline domains at the $2 \Theta$ angle range 12,15 , and 16 degree, respectively.

2.9. Determination of Shape and Size of Nanoparticles by Method of Scanning Electron Microscopy. Shape and size of particles were investigated by SEM "Hitachi S-4700." The diluted dispersion of cellulose nanoparticles was subjected to ultrasonic treatment for $5 \mathrm{~min}$. A drop of the diluted dispersion was applied onto a substrate and dried and the dry sample was coated with a thin layer of gold. Then the sample was placed in the microscope, evacuated, and electronic image of particles was obtained.

\section{Results and Discussion}

3.1. Treatment of MCC by SA at Room Temperature $\left(25^{\circ} \mathrm{C}\right)$. The effect of sulfuric acid concentration on structure and properties the cellulose were studied at $25^{\circ} \mathrm{C}$, for $1 \mathrm{~h}$. The study showed that solubility of the initial sample increased gradually from 5 to $30 \%$ in the range of the acid concentration from 50 to $60 \mathrm{wt} . \% \mathrm{SA}$; however, at the acid concentration $>60 \mathrm{wt} . \%$, the considerable rise in solubility of the cellulose was observed (Figure 1). When SA concentration reached $65 \mathrm{wt} . \%$, then MCC sample dissolved completely. 


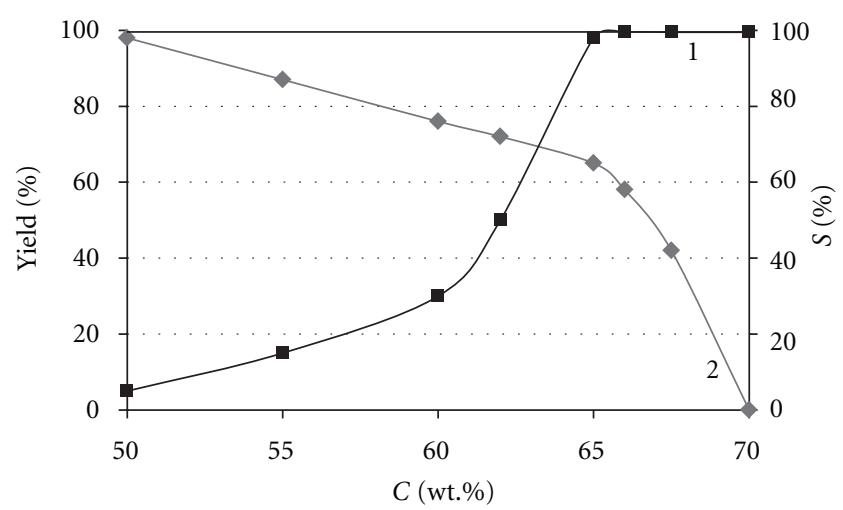

FIGURE 1: Solubility of MCC (1) and yield of regenerated cellulose (2) at $25^{\circ} \mathrm{C}$ as a function of sulfuric acid concentration.

Cellulose regenerated from $65 \mathrm{wt} . \%$ SA had yield about of $65 \%$, and its DP was 70-80. Increasing of SA concentration more than $65 \mathrm{wt} . \%$ led to diminution in yield of the regenerated cellulose. After treatment of the initial MCC sample with $70 \mathrm{wt} . \%$ SA, the dissolved cellulose cannot be regenerated from the acidic solution by dilution with water due to fast acidic depolymerization of cellulose and forming the water-soluble oligomers [7]. In this connection, the proposal regarding isolation of nanocellulose particles by means of treatment of initial cellulose with $70 \mathrm{wt} . \%$ SA at room temperature [38] seems unsuccessful.

According to $\mathrm{XRD}$ investigations, in the range of $\mathrm{SA}$ concentration from 50 to $60 \mathrm{wt} . \%$ the crystallinity degree and CI crystalline state of cellulose changed slightly (Figure 2). However at concentration higher than $64 \mathrm{wt} . \%$, the acidic treatment of MCC led to forming the regenerated cellulose having CII crystalline polymorph and low crystallinity. These results permitted us to find the following optimal conditions for preparation of amorphized cellulose with the maximal yield about $65 \%$ :

(i) concentration of SA: $65 \mathrm{wt} . \%$;

(ii) temperature: $\leq 25^{\circ} \mathrm{C}$;

(iii) time: $1 \mathrm{~h}$.

The obtained amorphized cellulose had low crystallinity (25$30 \%$ ), while its crystalline part consisted of crystalline polymorph CII only. Due to high content of amorphous phase, this product showed the increased enzymatic digestibility (Figure 3).

\subsection{Treatment of MCC by SA at Increased Temperature} $\left(45^{\circ} \mathrm{C}\right)$. Temperature $45^{\circ} \mathrm{C}$ for treatment of MCC with SA was chosen because it regarded as optimal for preparation of nanocellulose $[22,24,29]$. Solubility of MCC in SA at $45^{\circ} \mathrm{C}$ was higher, and yield after regeneration was lower than these features at $25^{\circ} \mathrm{C}$ (Figure 4). If the cellulose dissolved at $25^{\circ} \mathrm{C}$ cannot be regenerated from $70 \mathrm{wt} . \% \mathrm{SA}$ due to hydrolysis and the forming completely soluble oligomers, the cellulose treated at $45^{\circ} \mathrm{C}$ can turn into soluble oligomers already in $67 \mathrm{wt} . \%$ SA.

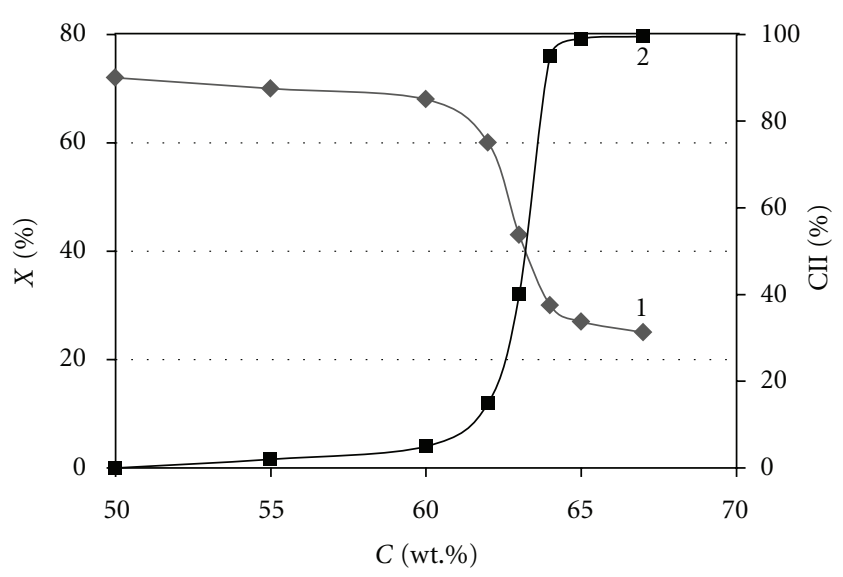

Figure 2: Crystallinity degree (1) and content of CII (2) as a function of sulfuric acid concentration at treatment temperature $25^{\circ} \mathrm{C}$.

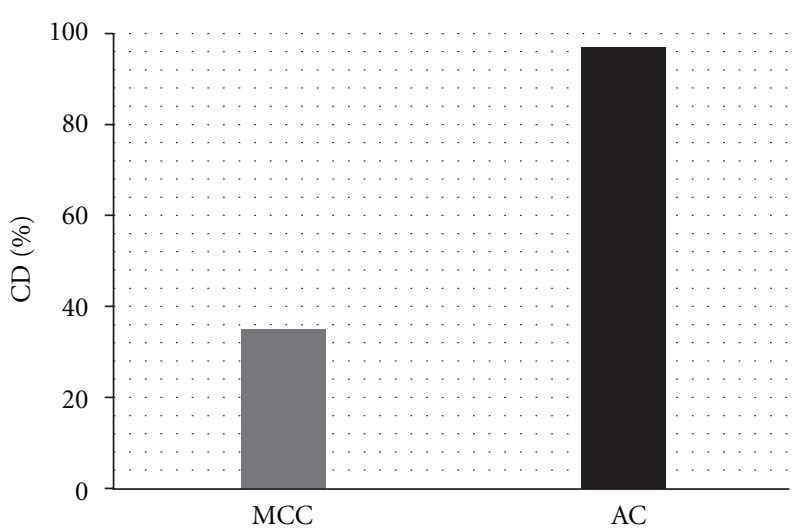

FIGURE 3: Conversion degree (CD) of the initial sample (MCC) and amorphized cellulose (AC) after enzymatic hydrolysis of the samples during $24 \mathrm{~h}$.

After treatment of MCC at $45^{\circ} \mathrm{C}$ with $50-60 \mathrm{wt} . \%$ SA, the crystallinity degree of the obtained cellulose samples also changed low, and these samples retained mainly the CI crystalline polymorph (Figure 5). When concentration of SA reached $65 \mathrm{wt} . \%$, main part of the initial cellulose dissolved. The cellulose regenerated from $65 \mathrm{wt} . \%$ SA had CII crystalline polymorph, decreased crystallinity $(25-30 \%)$ and low DP (40-50).

To obtain the high-crystalline nanocrystalline cellulose particles having CI polymorph, hydrolysis of initial cellulose materials with $63.5-65 \mathrm{wt} . \% \mathrm{SA}$ at $45^{\circ} \mathrm{C}$ was proposed [24, 29-31]. However, experimental results showed (Figure 5) that after treatment with $63.5 \mathrm{wt} . \%$ SA decrease in crystallinity of cellulose was observed, while the obtained sample consisted of mixture CI and CII polymorphs. If the initial cellulose was treated with $65 \%$ SA, then amorphized and depolymerized sample having CII polymorph was formed. Moreover, yield of the isolated cellulose was low, $20-30 \%$ only. Thus, the known conditions for preparation of nanocrystalline cellulose particles (NCP) are far from optimal.

To prepare really the high crystalline cellulose nanoparticles, the optimal concentration of SA at the acidic treatment 


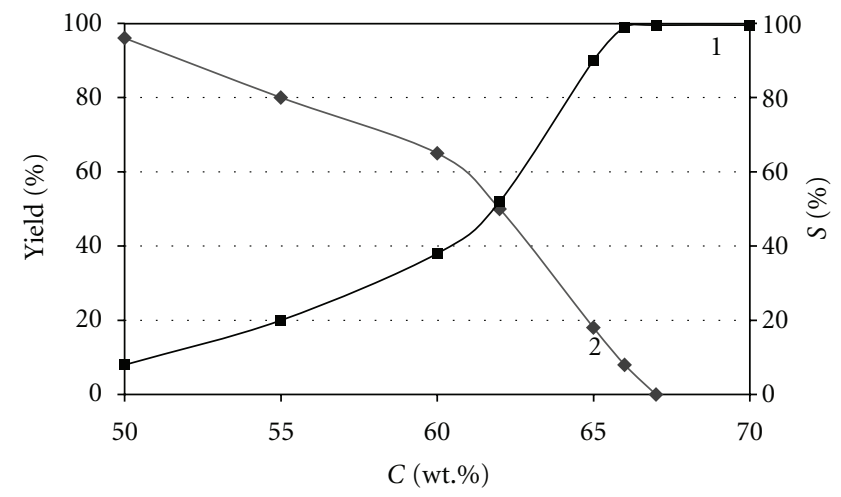

FIGURE 4: Solubility of MCC (1) and yield of regenerated cellulose (2) at $45^{\circ} \mathrm{C}$ as a function of sulfuric acid concentration.

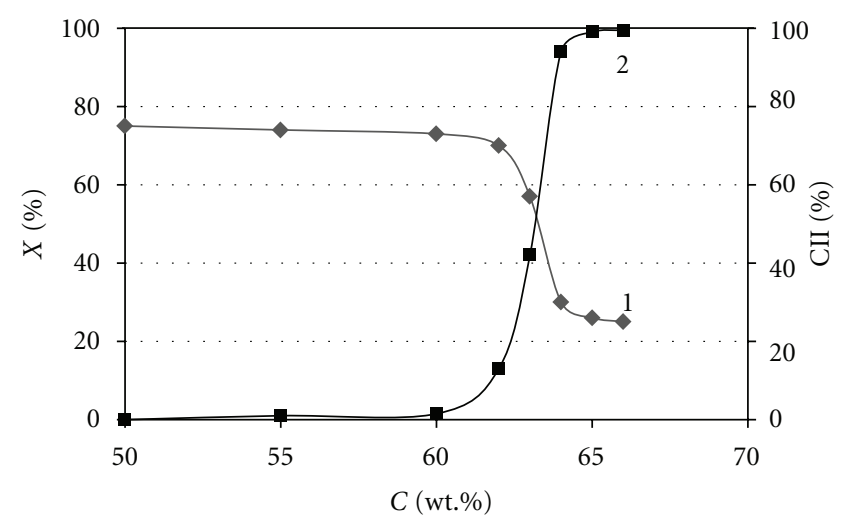

Figure 5: Crystallinity degree (1) and content of CII (2) as a function of sulfuric acid concentration at treatment temperature $45^{\circ} \mathrm{C}$.

should be in the range 57-60 wt.\%. After treatment of the initial sample with the optimal concentration of SA at $45^{\circ} \mathrm{C}$ for $1 \mathrm{~h}$ and the following high-power disintegration of the hydrolyzed cellulose in water medium, the rod-like NCP $(150-200 \times 10-20 \mathrm{~nm})$ can be isolated (Figure 6).

As known, the initial cellulose sample-microcrystalline cellulose-contains aggregates of nanocrystallites that join together by local lateral crystalline contacts. To isolate the free nanocrystalline particles, it is required to break the crystalline contacts between adjacent nanocrystallites in the aggregates of MCC. Treatment of MCC with 57-60 wt.\% SA causes etching of the lateral contacts and sulfonation of surface of individual nanocrystallites. As a result, the crystalline contacts are replaced by weaker amorphous contacts. However, sulfuric treatment of the MCC only is not enough for releasing the individual nanocrystallites because even the amorphous contacts join together by hydrogen bonds with average energy $20 \mathrm{~kJ} / \mathrm{mole}$ and additional Van der Waals bonds [39]. To breakdown these contacts and isolate the free NCP, it is required the high-power ultrasonic or mechanical disintegration of the acid-treated cellulose in the water medium during 10-20 min. Ultrasonic dispersers $(20-40 \mathrm{kHz})$ and high-pressure homogenizers (50-100 MPa)

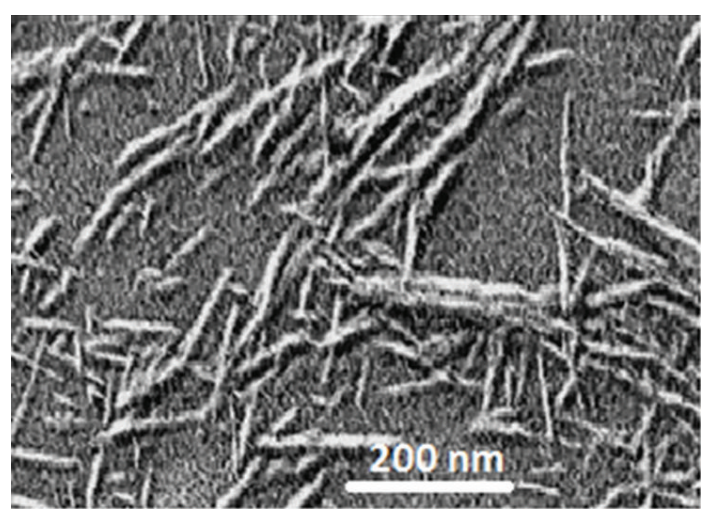

FIGURE 6: SEM image of rod-like nanocrystalline cellulose particles.

TABLE 1: Main features of the nanocrystalline cellulose particles.

\begin{tabular}{lc}
\hline Feature & Value \\
\hline Type of crystalline polymorph & $\mathrm{CI}$ \\
Crystallinity degree, \% & $73-75$ \\
Average particle length, nm & $150-200$ \\
Average particle width, nm & $10-20$ \\
Aspect ratio & $10-20$ \\
Degree of polymerization & $120-140$ \\
\hline
\end{tabular}

were used for this purpose. To prevent the reaggregation of nanoparticles, solid content of the acid-treated cellulose in water medium at the disintegration should not exceed 2-3\%.

The determined optimal conditions permit to isolate the NCP (nanowhiskers) with increased yield (65-70\%). The obtained NCP had CI crystalline polymorph and were characterized by the features in Table 1 .

\section{Conclusion}

The effect of concentration of sulfuric acid (SA) and temperature on structure and properties of cellulose sample (MCC) had been studied. Investigations of the room temperature treatment showed that solubility of the initial sample increased gradually from 5 to $30 \%$ in the range of the acid concentration from 50 to $60 \mathrm{wt} . \%$ SA. When SA concentration reached $65 \mathrm{wt} . \%$, then MCC sample dissolved completely. Cellulose regenerated from 65 wt.\% SA had CII crystalline polymorph and decreased the crystallinity degree. Increasing of SA concentration more than $65 \mathrm{wt} . \%$ led to decrease in yield of the regenerated cellulose, and after treatment of the initial sample with $70 \mathrm{wt} . \%$ SA the dissolved cellulose cannot be regenerated from the acidic solution by dilution with water. The method for production of amorphized cellulose by means of regeneration its solution in $65 \mathrm{wt} . \%$ SA was proposed. The obtained amorphized cellulose can be used as a promising substrate for enzymatic hydrolysis and producing the fermentable sugar-glucose.

At elevated temperature, that is, $45^{\circ} \mathrm{C}$, solubility of MCC in SA increases, while yield and DP decrease. Moreover, the cellulose treated at $45^{\circ} \mathrm{C}$ turns to non regenerable oligomers 
already at SA concentration of $67 \mathrm{wt} . \%$. After treatment of MCC with hot 50-60 wt.\% SA the crystallinity degree of the obtained cellulose samples changed slightly, and these samples retained mainly the CI crystalline polymorph. However, when concentration of SA reached $65 \mathrm{wt} . \%$, then regenerated cellulose was formed. This regenerated cellulose had CII crystalline polymorph, reduced crystallinity (25$30 \%)$, and low DP (40-50).

Combination of the optimal acidic treatment with the high-power disintegration permits obtaining the high-crystalline NCP $(150-200 \times 10-20 \mathrm{~nm})$ with the heightened yield (65-70\%). These nanoparticles can be used, for example, as a reinforcing nanofiller for various composites.

\section{References}

[1] K. Meyer and H. Mark, "For the crystallizable part of cellulose," Chemische Berichte, vol. 61, pp. 593-614, 1928.

[2] K. Freudenberg, W. Kuhn, W. Dürr, and W. Belz, "Hydrolysis of polysaccharides," Chemische Berichte, vol. 63, pp. 15101530, 1930.

[3] K. Hess, Chemistry of Cellulose and Its Satellites, Chemical \& Technology, Moscow, Russia, 1934.

[4] V. I. Sharkov, Hydrolytic Production, Forest \& Paper, Moscow, Russia, 1950.

[5] V. M. Nikitin, Wood and Cellulose Chemistry, Forest \& Paper, Moscow, Russia, 1960.

[6] N. A. Vedernikov and V. K. Kalnina, Wood Cell Wall and Its Changes at Chemical Treatments, Chemistry, Riga, Latvia, 1972.

[7] F. Camacho, P. Gonzalez-Tello, E. Jurado, and A. Robles, "Microcrystalline-cellulose hydrolysis with concentrated sulphuric acid," Journal of Chemical Technology and Biotechnology, vol. 67, pp. 350-356, 1996.

[8] M. Ioelovich and E. Larina, "Parameters of crystalline structure and their influence on the reactivity of cellulose I," Cellulose Chemistry and Technology, vol. 33, no. 1, pp. 3-12, 1999.

[9] P. H. Clifford, "Hydrocellulose—a summary of the literature," Journal of The Textile Institute, vol. 14, no. 3, pp. 69-77, 1923.

[10] A. Obolenskaya, Z. Eltinskaya, and A. Leonovich, Laboratory Manual on Wood and Cellulose Chemistry, Ecology, Moscow, Russia, 1991.

[11] V. I. Sharkov, Quantitative Chemical Analysis of Plant Raw Materials, Forest Ind, Moscow, Russia, 1976.

[12] R. Rowell, M.Handbook of Wood Chemistry and Wood Composites, CRC Press, Boca Raton, Fla, USA, 2005.

[13] D. Fengel and G. Wegener, Wood Chemistry, Ultrastructure, Reactions, Walter de Gruyter, Berlin, Germany, 1984.

[14] TAPPI Standard. Acid-insoluble lignin in wood and pulp, T222 om-02, 2002.

[15] X. M. Dong, J. F. Revol, and D. G. Gray, "Effect of microcrystallite preparation conditions on the formation of colloid crystals of cellulose," Cellulose, vol. 5, no. 1, pp. 19-32, 1998.

[16] M. Roman and W. T. Winter, "Effect of sulfate groups from sulfuric acid hydrolysis on the thermal degradation behavior of bacterial cellulose," Biomacromolecules, vol. 5, no. 5, pp. 1671-1677, 2004.

[17] I. Z. Selim, A. A. F. Zikry, and S. H. Gaber, "Physicochemical properties of prepared cellulose sulfates: II. From linen pulp bleached by the $\mathrm{H}_{2} \mathrm{O}_{2}$ method," Polymer-Plastics Technology and Engineering, vol. 43, no. 5, pp. 1387-1402, 2004.
[18] M. Ioelovich and A. Leykin, "Nano-cellulose and its application," SITA, vol. 6, no. 3, pp. 17-24, 2004.

[19] M. Ioelovich and A. Leykin, "Microcrystalline cellulose: nanostructure formation," Cellulose Chemistry and Technology, vol. 40, no. 5, pp. 313-317, 2006.

[20] M. Ioelovich, "Cellulose as a nanostructured polymer: a short review," BioResources, vol. 3, no. 4, pp. 1403-1418, 2008.

[21] M. Ioelovich, "Optimal conditions for isolation of nanocrystalline cellulose particles," Nanoscience and Nanotechnology, vol. 2, no. 2, pp. 9-13, 2012.

[22] Y. Habibi, L. A. Lucia, and O. J. Rojas, "Cellulose nanocrystals: chemistry, self-assembly, and applications," Chemical Reviews, vol. 110, no. 6, pp. 3479-3500, 2010.

[23] R. R. Lahiji, X. Xu, R. Reifenberger, A. Raman, A. Rudie, and R. J. Moon, "Atomic force microscopy characterization of cellulose nanocrystals," Langmuir, vol. 26, no. 6, pp. 44804488, 2010.

[24] Y. Li and A. Ragauskas, "Cellulose nano-whiskers as a reinforcing filler in polyurethanes," Advances in Diverse Industrial Applications of Nanocomposites, vol. 3, pp. 17-36, 2011.

[25] J. I. Morán, V. A. Alvarez, V. P. Cyras, and A. Vázquez, "Extraction of cellulose and preparation of nanocellulose from sisal fibers," Cellulose, vol. 15, no. 1, pp. 149-159, 2008.

[26] D. Y. Liu, X. W. Yuan, D. Bhattacharyya, and A. J. Easteal, "Characterisation of solution cast cellulose nanofibre-reinforced poly(lactic acid)," Express Polymer Letters, vol. 4, no. 1, pp. 26-31, 2010.

[27] L. Ludueña, D. Fasce, V. A. Alvarez, and P. M. Stefani, "Nanocellulose from rice husk following alkaline treatment to remove silica," BioResources, vol. 6, no. 2, pp. 1440-1453, 2011.

[28] M. Yu, R. Yang, L. Huang, X. Cao, F. Yang, and D. Lin, "Preparation and characterization of bamboo nanocrystalline cellulose," Bioresources, vol. 7, no. 2, pp. 1802-1812, 2012.

[29] D. Bondeson, A. Mathew, and K. Oksman, "Optimization of the isolation of nanocrystals from microcrystalline cellulose by acid hydrolysis," Cellulose, vol. 13, no. 2, pp. 171-180, 2006.

[30] S. Elazzouzi-Hafraoui, Y. Nishiyama, J. L. Putaux, L. Heux, F. Dubreuil, and C. Rochas, "The shape and size distribution of crystalline nanoparticles prepared by acid hydrolysis of native cellulose," Biomacromolecules, vol. 9, no. 1, pp. 57-65, 2008.

[31] G. Siqueira, J. Bras, and A. Dufresne, "Luffa cylindrica as a lignocellulosic source of fiber, microfibrillated cellulose, and cellulose nanocrystals," BioResources, vol. 5, no. 2, pp. 727$740,2010$.

[32] A. Zakharov, M. Voronova, M. Radugin, T. Lebedeva, and N. Trutnev, "Structure and properties of cellulose isolated from water dispersion of nano-whiskers by freeze-drying method," Chemistry of Plant Raw-Materials, vol. 4, pp. 31-36, 2010.

[33] H. Ono, Y. Shimaya, T. Hongo, and C. Yamane, "New aqueous dispersion of cellulose sub-micron particles," Transactions of the Materials Research Society of Japan, vol. 26, no. 2, pp. 569$572,2001$.

[34] H. Ono, T. Matsui, and I. Miyamoto, Cellulose dispersion, US Patent no. 6,541,627, 2003.

[35] R. Hashaikeh, T. Q. Hu, and R. Rerry, Crystalline sulphated cellulose II and its production from sulphuric acid hydrolysis of cellulose. US Patent Application no. 20100286387, 2010.

[36] M. Ioelovich, A. Leykin, and O. Figovsky, "Study of cellulose paracrystallinity," BioResources, vol. 5, no. 3, pp. 1393-1407, 2010.

[37] M. Y. Ioelovich and G. P. Veveris, "Cellulose II content determination by X-ray analysis using an internal standard," Wood Chemistry, vol. 2, pp. 10-14, 1983. 
[38] J. F. Revol, L. Godbout, X. M. Dong, D. G. Gray, H. Chanzy, and G. Maret, "Chiral nematic suspensions of cellulose crystallites-phase separation and magnetic field orientation," Liquid Crystals, vol. 16, no. 1, pp. 127-134, 1994.

[39] M. Ioelovich, "Nano-structural concept of papermaking," SITA, vol. 11, no. 1, pp. 52-60, 2009. 

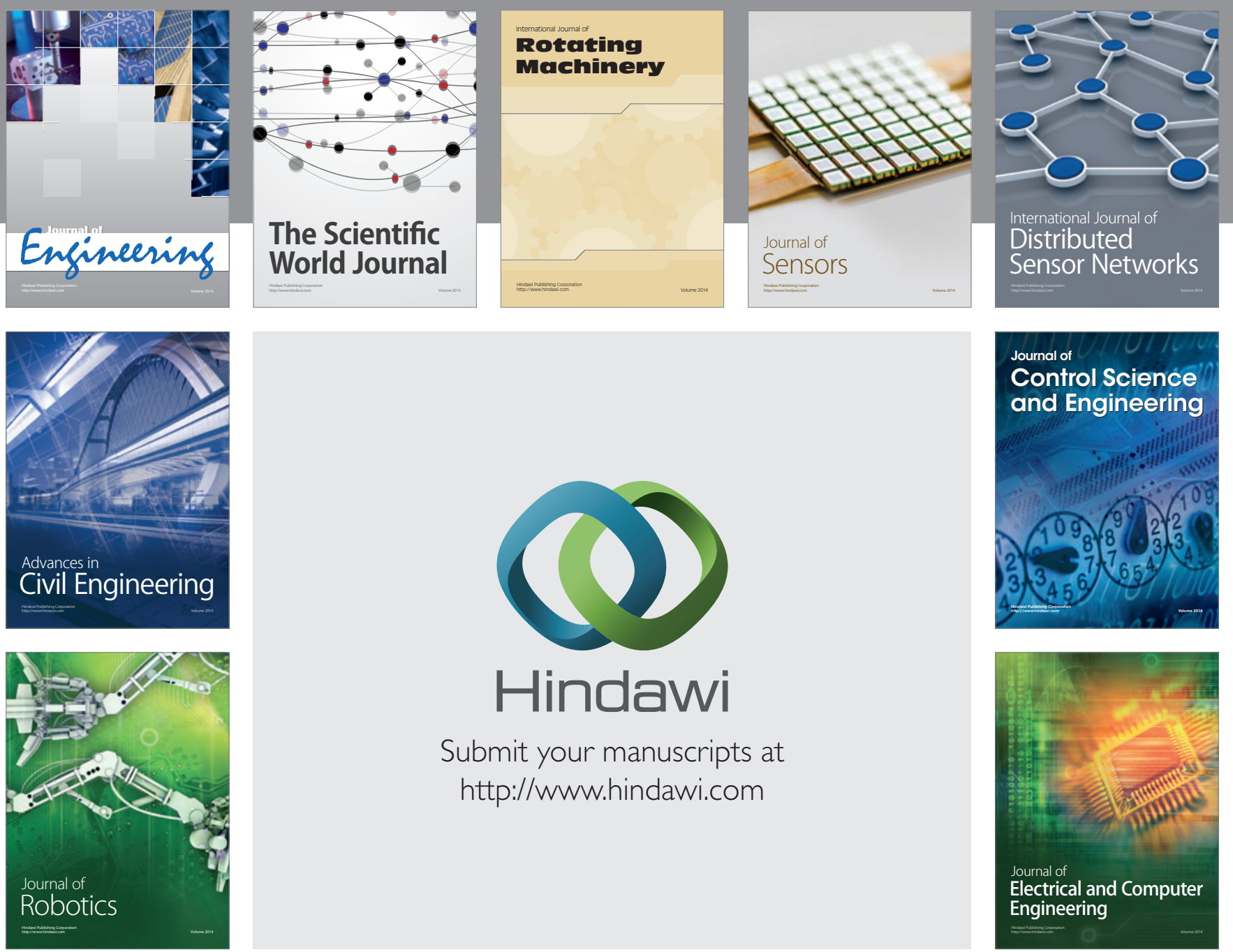

Submit your manuscripts at

http://www.hindawi.com
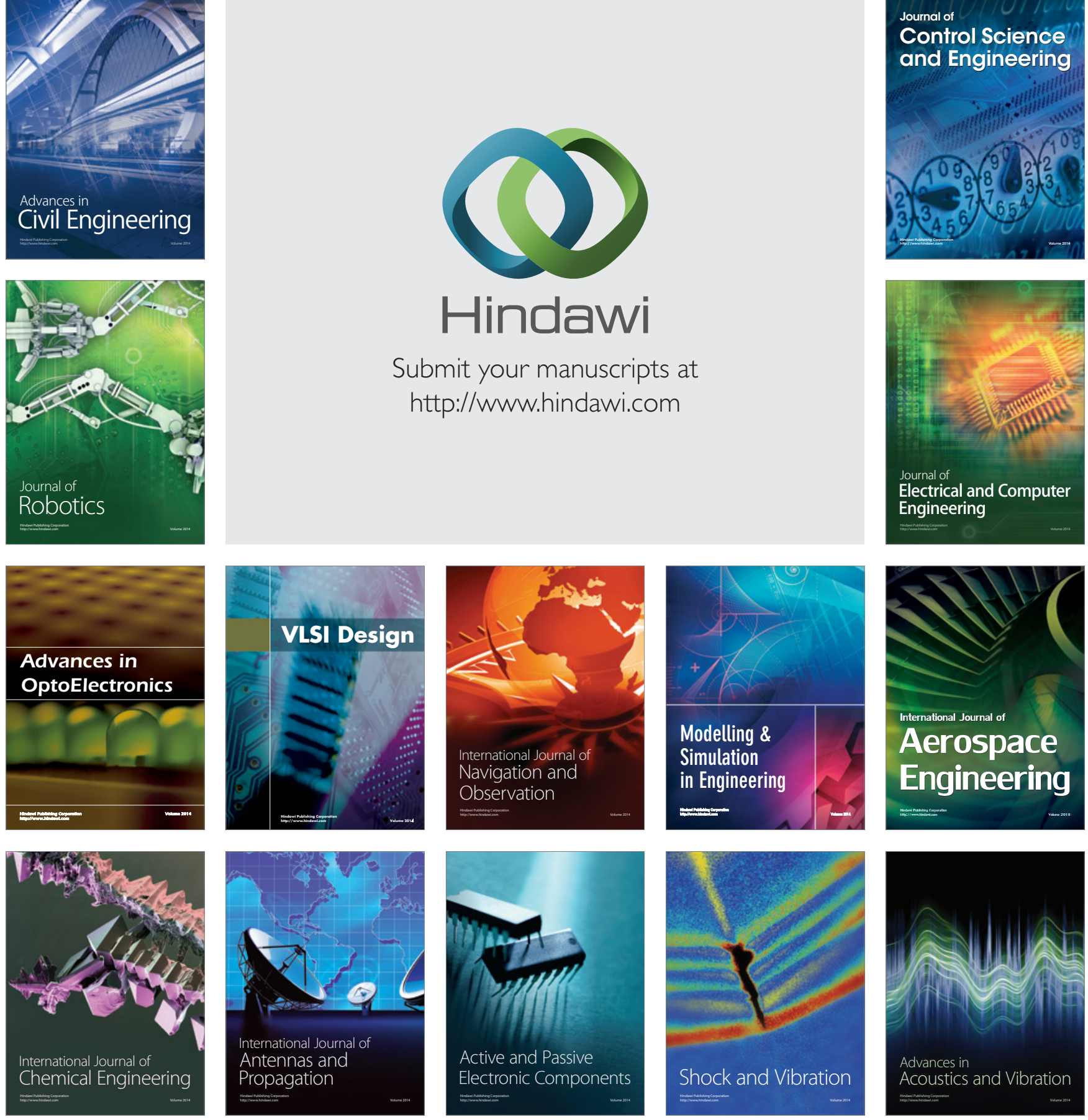